\title{
Teaching Exploration of Numerical Analysis Course Based on Online and Offline Blended Teaching Mode
}

\author{
Duan Mei ${ }^{1}$, Ruyun Chen ${ }^{1 *}$ \\ ${ }^{I}$ Faculty of Mathematics and Computer Science, Guangdong Ocean University, Zhanjiang, Guangdong 524088, \\ China \\ ${ }^{*}$ Corresponding author. Email: mathexp2014@126.com
}

\begin{abstract}
With the popularization of network information, curriculum teaching is facing reform and innovation, and the traditional teaching mode can't meet the teaching needs of contemporary college students. The online and offline blending learning mode can make good use of the network platform and make the teaching content more cutting-edge, novel, and rich, which has become the mainstream trend of college reform in China. This paper analyzed the situation of numerical analysis course, discusses the specific design process of online and offline mixed teaching mode in numerical analysis course, and the results showed that this teaching mode could improve the teaching effect to a certain extent.
\end{abstract}

Keywords: Numerical analysis, Online and offline, Blended teaching.

\section{INTRODUCTION}

The development of information technology has triggered a profound educational reform. Various learning resources and new teaching modes based on information technology emerge in an endless stream. MOOC, SPOC, flipped classroom, online and offline blended classroom and so on have become the new favorites in educational research and practice. In the current information age, faced with time fragmentation and diversified forms of knowledge acquisition, the traditional teaching mode has been unable to meet the needs of talent cultivation. The reform of the higher education teaching mode is imperative. At present, educators actively use platforms such as Superstar learning link, School Online, and Rain class to carry out the reform and exploration of online and offline mixed teaching modes such as MOOC and SPOC[1][2]. Predecessors have tried to apply it in advanced mathematics and pharmacy courses and achieved certain effects[3][4]. According to the characteristics of numerical analysis courses of information and Computing Science major of Guangdong Ocean University, this study discussed the reform of the online and offline blended teaching mode by using the Superstar learning link platform to provide a reference for the reform of online and offline blended teaching.

\section{INTRODUCTION OF BLENDED TEACHING}

As its name implies, Blended teaching is a teaching mode that combines the advantages of various teaching modes. Its teaching mode mainly combines online and online and offline. Blended teaching originated from the 2000 'White Paper on Educational Technology in the USA.' It was introduced into China in 2002. Its connotation is mainly to combine traditional teaching methods with modern network teaching and fully mobilize students' subjective initiative, enthusiasm and creativity by giving play to teachers' guidance and inspiration. The traditional teaching mode has some limitations but also has some advantages. For example, teachers and students can communicate and interact face to face in class, and teachers can better grasp the progress of students' learning. Online teaching has the advantages of stimulating students' interest in learning and fully exploiting resources. The combination of the two can help students gradually transition from shallow learning to deep learning. The integration of blended teaching mode in college curriculum teaching is not simply to establish teaching resources. It's not just about using online platforms and simply innovative teaching activities. Instead, it helps students learn the course better, using the easiest path to enhance the depth of students' course learning. In the ten-year 
Development Plan of Education Informatization (20112020), it is also clearly pointed out that the development goal of education informatization with Chinese characteristics should be formed. In the information age of "Internet +", blended teaching has become the main force to promote the teaching reform of colleges and universities in China.

\section{INTRODUCTION OF NUMERICAL ANALYSIS COURSE}

Numerical analysis, also known as the computational method, is a significant part of computational mathematics. It is a subject that studies the numerical calculation method and its theory and software implementation of solving various mathematical problems with computers. At the same time, numerical analysis is also the theoretical basis and foundation for computer program design and analysis of numerical results. It has the characteristics of high abstraction and rigorous science of pure mathematics and the features of the extensive application and highly technical aspects of practical experiments. It is a mathematics course with strong practicality. Mastering the basic knowledge of numerical calculation methods and proficiently using computers for scientific calculations have become indispensable tools for people to engage in scientific research and engineering applications. Therefore, most of the science and engineering majors in colleges and universities generally offer this course. The numerical analysis course is the core course of professional education for Information and Computing Science majors at Guangdong Ocean University. It is also a compulsory course for mechanical engineering majors and other science and engineering majors in Guangdong Ocean University. In line with the idea of laying a solid foundation for the follow-up courses, teachers complete the teaching plan through lectures, after-class discussions, and experimental analysis and evaluate students based on their exam scores, classroom performance, and homework. But in the long-term teaching process, I also found some problems.

\subsection{More teaching content and fewer teaching hours}

At present, our school's numerical analysis course has a total of 64 class hours, 4 class hours each week, including 48 theoretical class hours arranged in the first 12 weeks and 16 experimental class hours. Due to a large amount of teaching content and the derivation of many theories and calculation formulas in the teaching process is too complicated, the teachers are limited inclass hours, and difficult to choose the teaching content. As a result, the teachers are tired of catching up with the schedule, and some students are not easy to accept what they have learned, resulting in an unsatisfactory teaching effect. Dealing with the contradiction between less learning and more teaching is a problem in the education of numerical analysis courses and a problem in many other courses. Numerical analysis is not only to teach students to solve problems but also to cultivate students' ability to find, analyze, and solve problems and innovate.

\subsection{Pay too much attention to formula derivation and neglect practical ability}

Numerical analysis is a course that attaches equal importance to theory and practice, while the current teaching of numerical analysis focuses on the preciseness and completeness of theory. For example, the first 12 weeks of pure theory teaching have diluted the characteristics of combining practicality and experiment. Teachers' classroom teaching emphasizes the explanation of calculation methods and theories, and most of the teaching time is spent on deducing formulas and teaching theories. The teacher neglected the characteristics of combining numerical analysis courses with computer technology and ignored students' practical and experimental teaching. These lead to the severe disconnection between students' theory and application, and their understanding of algorithms is not deep enough.

\subsection{Students have differences in foundation and learning ability}

The fundamental courses of numerical analysis are mathematical analysis and advanced algebra. Numerical analysis course are generally offered in the second semester of sophomore year. Traditional undergraduate teaching mainly adopts the teacher-centered teaching mode. In such a teaching mode, with the same teaching rhythm, the teacher cannot give guidance to each student and cannot meet the needs of each student. As a result, students with a weak foundation find the content too difficult and progress too fast, while top students find the content simple and progress too slow.

\subsection{The assessment method is not reasonable}

The examination method mainly still focuses on a closed book examination. Most teachers agree that closed-book exams do not necessarily reveal students' actual level and ability. A student with a high level of ability may get average test results, while a student with a lower level and ability may do well on the test. It is because students spend a lot of time and energy cramming for their final exams. The consequence is that students think that they can pass the exam with a short burst but are unwilling to spend more time on in-depth thinking and fail to promote the accumulation and improvement of students' knowledge through the examination. 
All of the above seriously deviate from the original intention of the Ministry of Education to set up this course and do not fit in with our talent training objectives. Also, 'Internet + Education' has become the feature of the current new stage of education informatization. It can significantly improve the informatization teaching ability of professional teachers, promote the transfer of professional teaching from the on-site classroom to the Internet, promote students' autonomous learning ability, and thus effectively improve the teaching quality. Therefore, it is necessary to explore the multi-integration of online and offline teaching mode and reform the traditional teaching methods.

\section{NUMERICAL ANALYSIS OF THE ONLINE AND OFFLINE BLENDED TEACHING MODE CONSTRUCTION AND ACHIEVED RESULTS}

Relying on the online and offline blended course construction project of Guangdong Ocean University, the blended teaching mode of online self-learning and offline flipped classroom is adopted for 16 class hours of numerical analysis theory. To change the passive learning mode of students, the offline traditional teaching means and online modern teaching means are organically combined to give full play to their advantages. Finally, a teaching mode combining targeted teaching methods and flipped classrooms is formed, taking online courses as the teaching platform. Under the traditional teaching mode, teachers teach in class, and students practice after class. Change into the teaching mode of students learning and practicing before class and teachers teaching and practicing in class. This greatly enriched the classroom teaching content, let students with problems into the classroom and triggered students' enthusiasm to learn.

\subsection{Construction of online and offline blended teaching mode of the numerical analysis course}

\subsubsection{Education preparation before class}

Using the Superstar learning link platform, I upload the pre-recorded teaching videos, the question library, and the courseware made by myself to provide resource support for developing numerical analysis hybrid teaching activities. The task list is released to students through the superstar learning link and QQ group to watch videos, courseware, and other learning resources in advance. In the material setting, teachers make adequate preparations, mark each class's knowledge points and critical points, attract students through interesting form design, and set preview questions and thinking to guide students to think and solve. If students do not understand the questions, they can communicate with teachers through QQ or Superstar learning link in time. Teachers will summarize the questions and then answer them for students to improve students' interest in learning. Teachers can ask students to respond for preview tasks to ensure that each student sees the notice and is ready for class. To do these well, we can solve the problems mentioned above, such as teaching content, fewer teaching hours, and differences in students' basic and learning abilities, to a certain extent.

\subsubsection{Classroom teaching organization}

Since the teacher has assigned the next stage of education tasks in the pre-class stage, appropriate adjustments should be made in offline classroom teaching. Teachers can no longer focus on the derivation of calculation formulas and explaining theoretical knowledge but pay attention to strengthening basic knowledge and the practical application and practice of knowledge points and organizing students to discuss in groups in class. Students have generally mastered the essential knowledge content of the next lesson through online previews before class, so teachers should pay attention to the interaction and communication with students in class. Teachers can set up thematic classroom discussion activities based on students' online knowledge learning. The content discussed in class can deepen and extend online preview content or promote an algorithm idea. With the help of complete discussion in offline classes, students' interest in knowledge learning is stimulated, and their excellent habits of deep thinking are cultivated.

\subsubsection{Sublimation of after-class teaching}

After each class, the teacher will publish homework in The Superstar learning link. After students submit assignments regularly, the teacher will correct them, and the scores will be directly counted in the Super Star learning channel. Teachers also need to answer questions online in the QQ group and Superstar learning link to get students' learning feedback in time. It will help students consolidate what they have learned and enable teachers to reflect on teaching according to students' feedback to improve teaching methods and improve teaching effects. In addition, the teacher should summarize the mistakes that are easy to occur in the teaching process, and post them to the QQ group, so that students can think, consolidate and improve pertinently, and encourage students to share their learning experience. It helps teachers to grasp the learning situation of the whole class, and then teachers can guide and supervise students in a targeted way.

\subsubsection{Assessment system}

The numerical analysis course forms the learning process result by the comprehensive learning situation 
of each link. The grade ratio is: the ordinary performance score is $40 \%$, the final exam is $60 \%$. Ordinary scores include: watching videos and course materials accounted for $10 \%$; Homework $10 \%$; Literature search, classroom discussion, and after-class communication accounted for $10 \%$, and experimental results accounted for $10 \%$. This kind of assessment method can effectively solve the problem that the abovementioned assessment method is not reasonable.

\subsection{The results obtained by the teaching model}

Students' final exam scores have been significantly improved, and the failure rate has been substantially reduced. The students' interest in numerical calculation methods has been enhanced significantly. In 2020, students of the course worked together in groups to solve practical engineering problems by using numerical calculation methods and won two undergraduate innovation and entrepreneurship training programs. In the National university students' mathematics model competition in 2021, three teams I led won prizes. The construction of online and offline blended teaching mode effectively promotes students' absorption and internalization of numerical analysis knowledge systems and cultivates students' comprehensive ability of practice and innovation.

\section{CONCLUSION}

The formation of online and offline blended teaching mode is not achieved overnight, and it needs to be improved continuously by combining theory and practice. It should strengthen the construction of teaching staff, deepen the reform of teaching content, teaching methods, and teaching means, and continue to improve the construction of teaching materials, attach importance to theoretical teaching, and strengthen practical teaching. The online and offline teaching mode of numerical analysis course should be improved mainly from the following aspects: Firstly, we need to establish a reasonable knowledge structure and attach importance to all aspects of course teaching; Secondly, set up and perfect the numerical analysis test question bank and practice question bank; Thirdly, we need to prepare practical application cases related to numerical analysis for classroom discussion; Fourthly, make full use of network resources and environment, constantly improve and update curriculum resources, and create a diversified teaching environment. Through the above improvements, the teaching quality of the online and offline blended teaching mode will be enhanced.

\section{ACKNOWLEDGMENTS}

The work described in this paper was supported by the Online and Offline hybrid Course Construction Project of Guangdong Ocean University, the Offcampus Practice Teaching Base Construction Project of Guangdong University Students (No.570419006), and the Collaborative Education Project of IndustryUniversity Cooperation of the Ministry of Education (Nos.201901035062, 202002140011, 202101055003).

\section{REFERENCES}

[1] Wen Zhang, Li Su, Bo Xu, Qiang Zhang, Zhen Yang.Research on Online and Offline Mixed Golden Course Based on Flipped Classroom[J]. Advances in Social Science Education and Humanities Research, 2020,480:222-226.

[2] Duan Mei. Research on Multi-Integrated Online and Offline Teaching Model in the Post-Epidemic Era - Taking Numerical Analysis Course as an Example [J]. Advances in Social Science Education and Humanities Research, 2020,480:356-359.

[3] Lv R X, Sun W J, Ma J. Exploration of Online and Classroom Mixed Teaching Mode in Advanced Mathematics[J] Journal of Jilin Institute of Chemical Technology , 2021,38(08):50-53.

[4] Lv F J, Xie X L, Gao P Z. Research on online and offline blended Teaching mode of Pharmacy course based on SPOC $[\mathrm{J}]$. Journal of Shangqiu Normal University,2021, 37 (3): 102-105. 